\title{
Control of smoke flow using a jet-fan in an underground car park
}

\author{
Marek Borowski ${ }^{1, *}$, Marek Jaszczur ${ }^{1}$, Michat Karch $^{1}$, Tomasz Burdzy ${ }^{1}$ \\ ${ }^{1}$ AGH University of Science and Technology, 30 Mickiewicza av., 30-059 Kraków, Poland
}

\begin{abstract}
Ventilation systems are used to provide ventilation for covered car parks and to control the smoke in the event of fire. In this paper the interaction between the fire ceiling jet and the flow driven by jet-fans is studied using CFD simulations. There is a number of parameters that can affect the flow of smoke that need to be considered. To avoid mistakes, fluid flow visualisation is highly required as well as in order to directly compare the different design variants. One of the best option to make flow analysis is to performed Computational Fluid Dynamics simulations (CFD). By CFD it is possible to detailed analyse and keep control of the flow of fluid, heat transfer and other related phenomena. It also helps predict the contamination level of Carbon Monoxide, heat and smoke intensity and distribution. In this study, CFD simulations were used to design, test and compare different design of a fire ventilation system. The research drew attention to the location of jet-fan type fans. The main objective of the study was to assess the impact of jet-fans on fire and to check if it is possible to evacuate people from the garage in less than 10 minutes. The simulation results emphasize the important location of the different elements on the functionality and efficiency of a fire protection system. Due to the evacuation of people from the garage, the simulation results suggest a 10 minute safety time for evacuation. During this period, high visibility and oxygen concentration, as well as low temperature allow for rapid evacuation.
\end{abstract}

\section{Introduction}

For modern buildings, the installation of a mechanical ventilation system is essential to provide the required level of air quality and thermal comfort at favourable energy consumption throughout the whole year $[1,2]$. Besides the creation of an excellent indoor environment, an important task of mechanical ventilation is to ensure fire safety $[3,4,5]$. For big underground car parks typical, e.g., for large commercial buildings, fire ventilation with jet-fans to move the polluted air to the main ventilation shafts has become popular and is being increasingly preferred over traditional ducted systems [6]. This system can be used both as day to day ventilation to remove airborne pollutants and as fire ventilation.

The fire ventilation exhausts the excessive heat and combustion products originating from the fire and simultaneously supplies fresh air to the car park to increase the safety of evacuated people and of the firemen. Regardless of the design standard used, it is crucial to verify the correctness of the proposed solution by numerical analysis (CFD) [7].

The CFD simulations present an efficient tool to analyse systems involving heat and mass transfer in a thorough and sophisticated manner by numerical models and to provide a view of the flow fields which would be otherwise difficult to visualize. The Fire Dynamics Simulator (FDS) has become a popular CFD tool to describe the evolution of fire by solving a large eddy simulation form of the Navier-Stokes equations $[8,9]$.
The FDS is often combined with specific software to create the input geometry such as PyroSim and to read the FDS output fires and produce animations such as Smokeview [10]. CFD models, in general, are better predictors than empirical models.

The aim of this study was to design and evaluate a fire ventilation system with jet-fans in an underground car park. The main task of the analysed ventilation system was to remove heat release and toxic fumes from garage space area . Alternative configurations were tested, using various location of the jet-fans and exhaust shafts, and different the air flowrate exchange rate. The FDS and associated computer software were used to account for the complex geometry of the car park including walls, columns, beams, cars, and the jet-fans.

\section{Combustion products originating from fire}

The knowledge obtained by studying the consequences of fire on human beings implies that combustion products can be even more dangerous to human health than the other fire related phenomena.

The combustion products originating from fire diminish the oxygen content in the air, suppress the ability of humans to think clearly, diminish visibility and orientation ability of evacuated people, and create preconditions for panic. Besides, they directly affect human health in two different ways - as smoke and as

Corresponding author: borowski@agh.edu.pl 
toxic gasses. As the most dangerous combustion product is considered carbon monoxide $[11,12,13]$.

\section{Design models of the fire ventilation system}

Design of the ventilation system: The potential heat and combustion products generated in the underground car park of a commercial building were exhausted by an under pressure ventilation system with jet-fans. The pressure difference between the exhaust and the supply pressure was $20 \%$. The fresh ventilation air was supplied through an access ramp and fire grilles.

Simulation model: The simulation model was created in FDS software, version 6.7.1 [13], for a calculation uniform structural grid of $0.15 \times 0.15 \times 0.15 \mathrm{~m}$ was constructed. The model represents a controlled fluid flow during a fire emergency. The calculation is governed by Navier-Stokes and energy equations suitable for heat-induced flows with low velocity to exhaust smoke and heat from the site, using the Dynamic Smagorinsky model [14]. Smokeview software [13] was used to visualise the fluid flow during a fire emergency. Parameters of the fire used during calculations are shown in Table 1, while parameters of the jet-fans are included in Table 2. Figures 1 and 2 show the flow of air particles from a jet-fan and the air flow when 5 jet-fans work in the car park respectively.

Table 1. Parameters of the design fire

\begin{tabular}{cccc}
\hline $\begin{array}{c}\text { Part of design } \\
\text { fire }\end{array}$ & $\begin{array}{c}\text { Heat Release Rate } \\
\text { per Unit Area } \\
\left(\mathrm{kW} / \mathrm{m}^{2}\right)\end{array}$ & Ignition time (s) \\
\hline Car 1 (middle) & \multicolumn{2}{c}{952.38} & 0 \\
\hline Car 2 (left) & \multicolumn{2}{c}{222.22} & 600 \\
\hline Car 3 (right) & \multicolumn{2}{c}{222.22} & 900 \\
\hline $\begin{array}{c}\text { Summary Heat } \\
\text { Release }\end{array}$ & $\begin{array}{c}\text { Radiative } \\
\text { Fraction }\end{array}$ & $\begin{array}{c}\text { Soot } \\
\text { Yield } \\
(-)\end{array}$ & $\begin{array}{c}\text { Heat of } \\
\text { Combustion } \\
(\mathrm{kg} / \mathrm{kg})\end{array}$ \\
\hline Rate $(\mathrm{kW})$ & 0.3 & 0.1 & 25000 \\
\hline 9000 & \multicolumn{4}{c}{}
\end{tabular}

Table 2. Parameters of jet-fans

\begin{tabular}{cc}
\hline Fan Diameter $(\mathrm{m})$ & 0.355 \\
\hline Thrust $(\mathrm{N})$ & 40 \\
\hline Volume flow $\left(\mathrm{m}^{3} / \mathrm{s}\right)$ & 1.82 \\
\hline Volume flow $\left(\mathrm{m}^{3} / \mathrm{h}\right)$ & 6550 \\
\hline Outflow velocity $(\mathrm{m} / \mathrm{s})$ & 18.4 \\
\hline case height $(\mathrm{m})$ & 0.6 \\
\hline case width $(\mathrm{m})$ & 0.6 \\
\hline case length $(\mathrm{m})$ & 1.8 \\
\hline
\end{tabular}

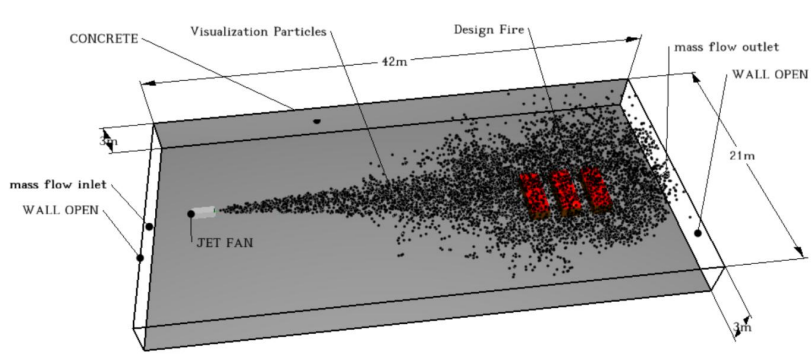

Fig. 1. Visualization of the air stream by a jet-fan in FDS software

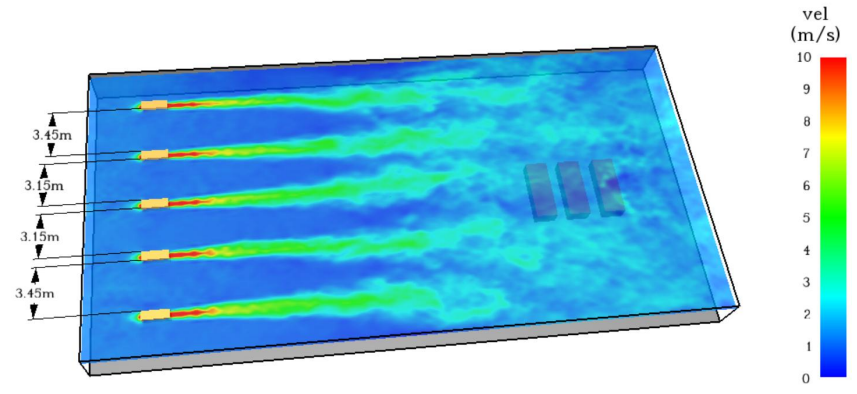

Fig. 2. Visualization of air flow from jet-fans.

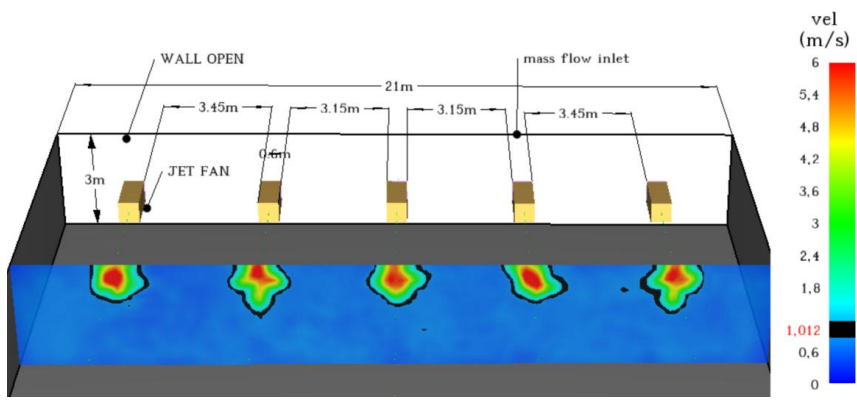

Fig. 3. Visualization of the air stream with a jet-fan in the FDS program version 6.7.1.

The outdoor air temperature was assumed to be $25.0{ }^{\circ} \mathrm{C}$. The atmospheric pressure was assumed to be $101.3 \mathrm{kPa}$. The entrance and exit were assumed to be $21.0 \mathrm{~m}$ in width and $3.4 \mathrm{~m}$ in height. The airflow path was assumed as a two-way flow with one opening and no wind pressure.

CFD analysis was done for underground parking with mechanical ventilation (one or five jet-fan) and 3-parked cars each (Fig. 1). To simplify the shape, the authors omitted the entrance, exit, elevators, staircases, etc. A was $42.0 \mathrm{~m}$ in length, $21.0 \mathrm{~m}$ in width, and $3.0 \mathrm{~m}$ in height. An air supply opening and an exhaust air opening for mechanical ventilation were included in the inner wall of each lot. The layout of the jet-fan in the car park is shown in Figure 3.

A single car fire is designed by stipulating the surface densities $952.38(\mathrm{~kg} / \mathrm{m} 2)$ of the fuel over the car. The calculations were accepted, that the fuel with heats of combustion and evaporation equal to $25000 \mathrm{~kJ} / \mathrm{kg}$, respectively. Once the ignition temperature is reached, the rate of evaporation depends on the amount of heat release from the fire. The predicted HRRs are in good agreement with experimental data during most stages of the car fire. The maximum HRR reaches about 9.0 MW for a three-car fire. When fire spreads from one burning car to another by 
contact with the flame or by thermal radiation, the ignited car has the same HRR. In this paper, ignition takes place when the temperature on the surface of the fuel tank exceeds $400 \mathrm{oC}$.

Figure 4 shows the development of HRR of car fires in an underground car park. It indicates that the fire can be classified into three stages, namely an initial stage, a fastdeveloping stage with high HRR, an extinction. The initial stage of about $10 \mathrm{~min}$ has rather low HRR. After that, the fire develops rapidly and after 20 min reaches a maximum value.

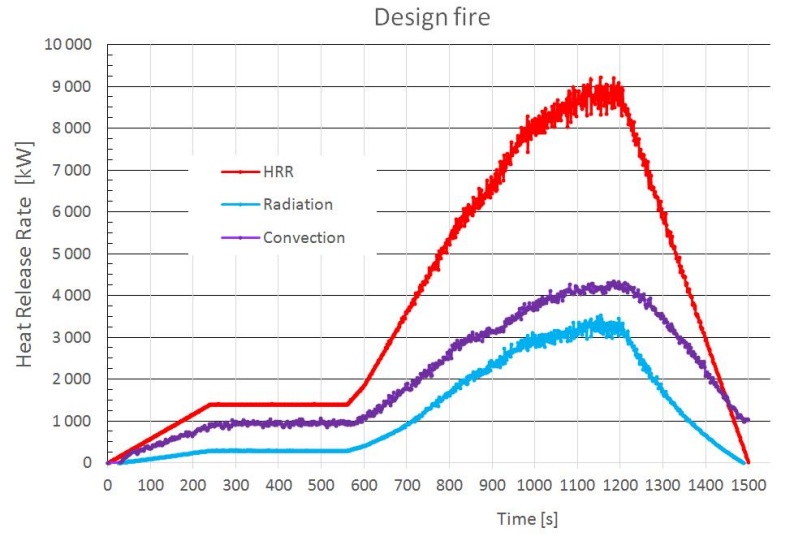

Fig. 4. Heat release rate of adopted design fire

\section{Results and discussion}

In this paper, the effect of ventilation on the fire spread and smoke movement in a large underground car park are simulated. Heat release rate (HRR) is regarded as a principal factor of fire. In order to simulate fire spread and smoke movement in an underground car park, a three-car that ignite from each other, fire is simulated to obtain HRR data.

Extraction volume flow is $1.82 \mathrm{~m} 3 / \mathrm{s}$, for one jet-fan, corresponding to extraction rates of $2.51 / \mathrm{h}$ air changes per hour for scenario 1, 2 and rates of $12.41 / \mathrm{h}$ air changes per hour in scenario 3, 4 respectively.

Considered two scenario of different distance jet-fan from the car, in the scenario of 1 and 3 the distance is $25.4 \mathrm{~m}$, in the scenario of 2 and 4 the distance is $4.2 \mathrm{~m}$.

Four selected scenario were presented for detailed analysis. Table 3 shows the development of HRR of car fires in an underground car park under different ventilation conditions. As shown in table 3, visibility is maintained in most areas, enabling evacuation to take place. Compared the scenario $1-4$, we will notice that visibility is improved by ventilation, and the extraction rate of $12.41 / \mathrm{h}$ air changes per hour improves visibility as compared with that of $2.51 / \mathrm{h}$ air changes per hour. The location of the jet-fan from the fire is also an important issue. For scenario 2 and 4 , good visibility is noticed in the long term.

However, with a well-developed fire, up to 5 fans can not help removing fumes from the garage, which is associated with the development of a fire by taking additional air. Figures 5 and 6 give detailed temperature distributions and flow fields under different ventilation systems.
Table 3. Smoke visualisation with time for different scenario(s)

\begin{tabular}{ccc}
\hline \multirow{2}{*}{$\begin{array}{c}\text { Time } \\
\text { (s) }\end{array}$} & Scenario 1. & Scenario 2. \\
\hline 60 & 1 jet-fan, 25.2 $\mathrm{m}$ to fire & 1 jet-fan, $4.2 \mathrm{~m}$ to fire \\
\hline & &
\end{tabular}

120
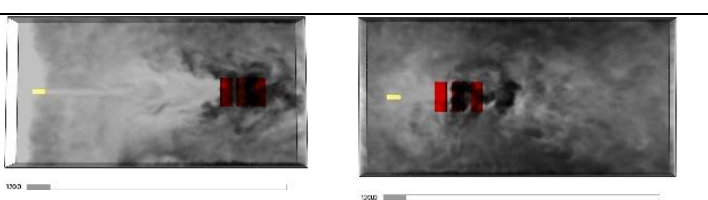

240
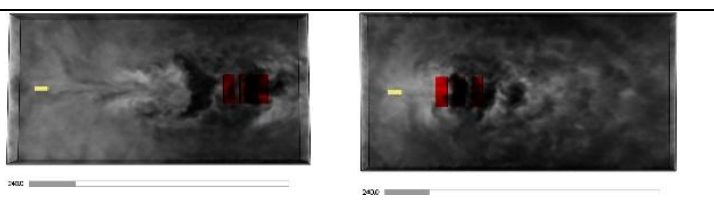

480
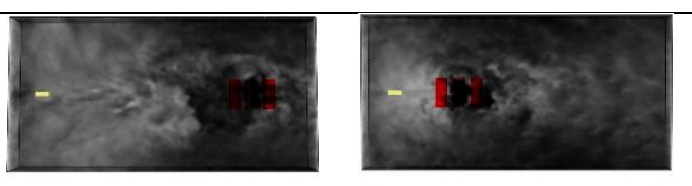

700
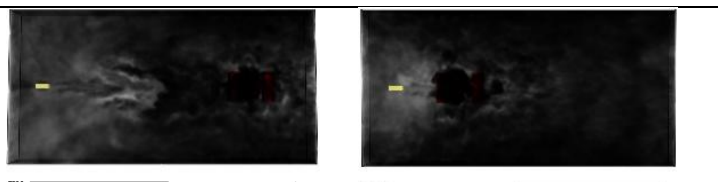

1200
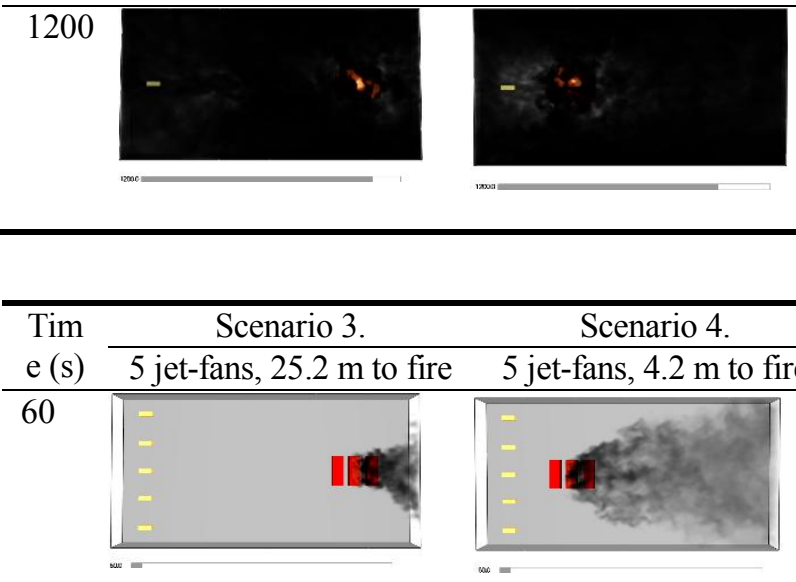

Scenario 4.

120
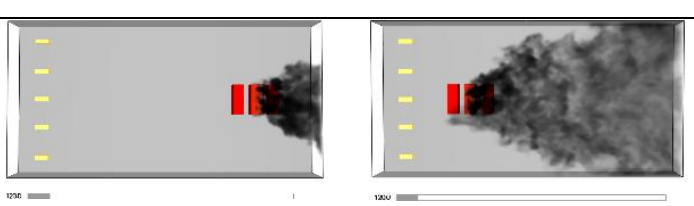

240

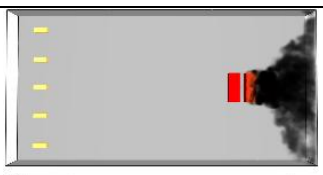

sos
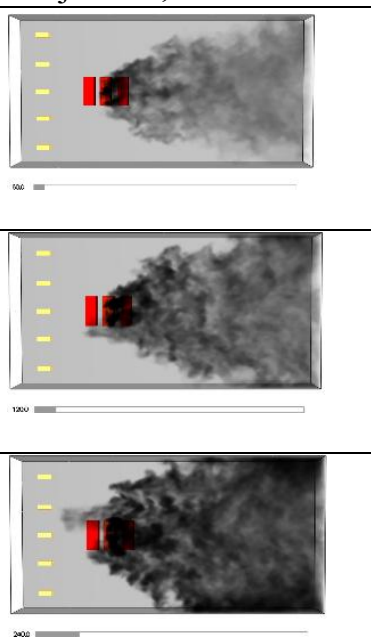

$=$ 

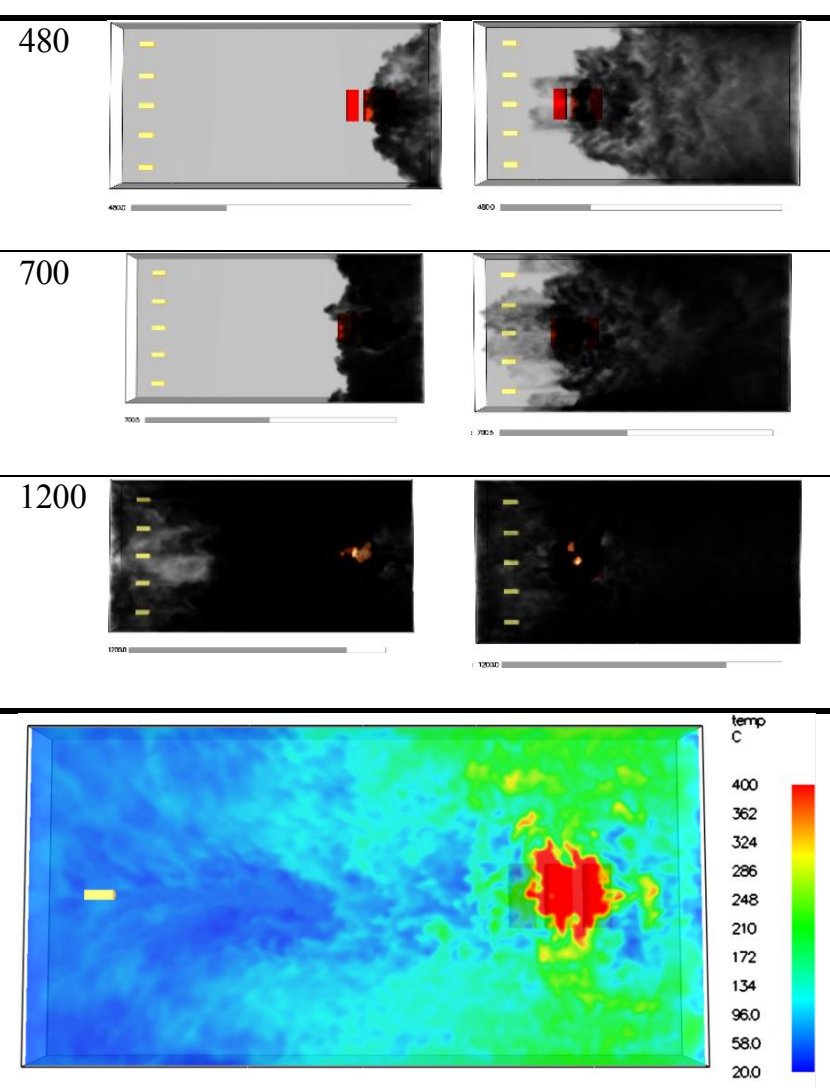

$1200.0 \square$ height $\mathrm{z}=2.55 \mathrm{~m}$, after $1200 \mathrm{~s}$

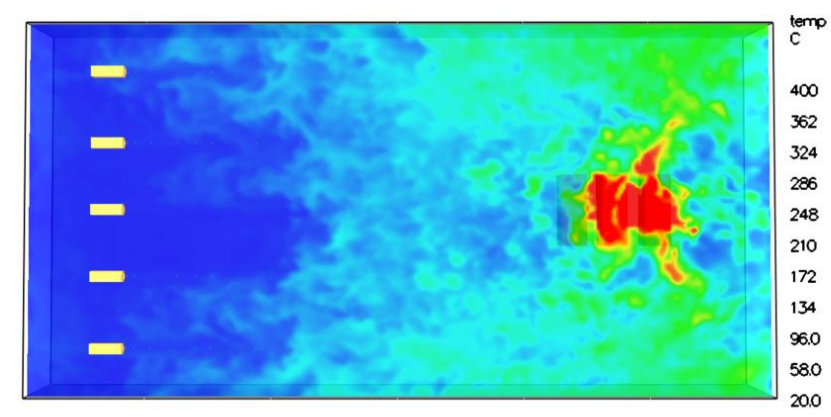

1200.0

Fig. 6. Temperature contour in Scenario 3. at height $z=2.55 \mathrm{~m}$, after $1200 \mathrm{~s}$

\section{Conclusion}

Numerical simulations of fire development in a large underground car park are carried out using the FDS code. Initially, a single car fire is simulated by specifying the surface densities of the fuel on the top of the cars.

The effect of ventilation on the fire spread and smoke movement in a large underground car park with 3 cars are then simulated. The heat release rate and instantaneous soot concentrations, as well as temperature distributions, are presented. The results have shown that the fire ventilation system was not able to sufficiently ventilate the large underground car park.
For fire spread between cars and for different ventilation systems, results show a multi-stage phenomenon for fire development. Results show that the extinction of the fire occurs due to lack of oxygen. After that, with ambient air drawn into the car park, again maybe a quickly developed fire is re-ignited.

Ventilation accelerates various stages of fire development. With regards to evacuation, simulation results suggest a safety time of $10 \mathrm{~min}$ for evacuation. During this period, high visibility and oxygen concentration, as well as low temperature and soot concentration, allows timely evacuation.

The present work was partially supported by the Polish Ministry of Science (Grant AGH No. 16.16.210.476).

\section{References}

1. S.J. Ahn, H.M. Kwon, G.H. Kim, J.H. Yang, Study of Securing Required Ventilation Rates and Improving Mechanical Ventilation Systems for Underground Parking Lots, Journal of Asian Architecture and Building Engineering, 15(3), pp. 659-665 (2016)

2. T. Burdzy, M. Borowski, Analysis of the correctness projection of jet-fan isothermal outflow stream, Rynek Instalacyjny 1-2, pp. 19-22 (2019)

3. M. Jaszczur R. Nowak, J. Szmyd, M. Branny, M. Karch, W. Wodziak, An application of SPIV technique to experimental validation of the turbulence model for the air flow in the intersection of the mining face with the ventilation gallery, Journal of Physics. Conference Series ; ISSN 17426588. vol. 318, pp. 1-6 (2011).

4. M. Branny, M. Karch, W. Wodziak, M. Jaszczur., R. Nowak, J. Szmyd, An experimental validation of a turbulence model for air flow in a mining chamber, Journal of Physics. Conference Series ; ISSN 17426588. vol. 530, s. 012029-1-012029-8. Bibliogr. s. 012029-8 (2014)

5. J. Szmyd, M. Branny, M. Karch, W. Wodziak, M. Jaszczur, R. Nowak, Experimental and numerical analysis of the air flow in T-shape channel flowArchives of Mining Sciences; ISSN 0860-7001. vol. 58, 2, pp. 333-348 (2013)

6. X. Deckers, S. Haga, N. Tilley, B. Merci, Smoke control in case of fie in a large car park: CFD Simulations of Full-Scale Confiurations", Fire Safety Journal, 57, pp. 22-34 (2013)

7. J.C. Viegas, The use of impulse ventilation for smoke control in underground car parks, Tunneling and Underground Space Technology, 25(1), pp. 42-53 (2010)

8. S. Lu, Y.H. Wang, R.F. Zhang, H.P. Zhang, Numerical Study on Impulse Ventilation for Smoke Control in an Underground Car Park, Procedia Engineering, 11, pp. 369-378 (2011)

9. X.G. Zhang, Y.C. Guo, C.K. Chan, W.Y. Lin, Numerical simulations on fire spread and smoke 
movement in an underground car park, Building and Environment, 42(10), pp. 3466-3475 (2007)

10. R. Wadhwani, D. Sutherland, A. Ooi, K. Moinuddin, G. Thorpe, Verifiation of a Lagrangian particle model for short-range fiebrand transport, Fire Safety Journal, 91, pp. 776-783 (2017)

11. European Committee for Standardization, EN 121013 Smoke and heat control systems - Part 3: Specifiation for powered smoke and heat control ventilators (Fans), CEN, Brussels, European Union (2016)

12. BSI Group BS 7346-7, Components for smoke and heat control systems. Code of practice on functional recommendations and calculation methods for smoke and heat control systems for covered car parks, BSI Group, London, United Kingdom (2013)

13. NEN 6098, Smoke control systems for powered smoke exhaust ventilators in car parks, ICS-CODE 13.220.20 (2012)

14. M. Germano, U. Piomelli, P. Moin, W.H. Cabot, A dynamic subgrid-scale eddy viscosity model, Physics of Fluids A: Fluid Dynamics, 3 pp. 1760-1765 (1991) 